\title{
Goals Achieved, Challenges to Conquer
}

This is an interesting time for our journal. There are several important developments to be pointed out in this introductory note.

Shortly before completing the fourth volume of Acta Baltica Historiae et Philosophiae Scientiarum, we received the good news that our journal has been considered by Scopus as meeting its standards. Since this day, all the papers published in our journal, from the very first issue in 2013, have been included in the Scopus database. This is a very important development because it makes our journal much more visible. More colleagues will be reading it and discussing important issues with our authors. This will add citations and enable us to start the process of introducing an Impact Factor to the journal. As Editor-inChief, I am deeply grateful to our editors, the Editorial Board members and, most importantly, to our authors for providing us with high-quality work. These people are all known to our readers. However, there is a group of helpful colleagues whose names cannot be revealed to the public but whose contribution to the success of the journal is by no means less important-our peer-reviewers who have done a truly invaluable job. Needless to say, however, several of these colleagues have been active in different capacities while contributing to the journal.

Another important development concerns the position of the Executive Editor of the journal. I am very happy to welcome Dr. Amirouche Moktefi, my colleague at the Tallinn University of Technology and an active member of the Estonian Association for the History and Philosophy of Science. Amirouche took up the job of Executive Editor only a few months ago but already has successfully contributed to the process of completing the current issue.

I am also very pleased to welcome Professor Sven Ove Hansson, our colleague from the Royal Institute of Technology (KTH) in Stockholm, as the Editorial Board member of our journal.

A few words about the content of the current issue. As usual, we have tried to keep a balance between philosophy and history of science, and have succeeded in this task by and large. The current issue has expanded the range of authors as much as possible. None of the authors of the issue has contributed to our journal before. From the aspect of philosophy, you can find an interesting analysis 
of the Cartesian eternal truths by Danielle Macbeth and an insight into the development of Euler-type diagrams by Jens Lemanski. Amirouche Moktefi, our new Executive Editor, has contributed with a thrilling overview of logic books in the library of Lewis Carrol, the famous author of Alice in Wonderland, who was also a well-known mathematician and logician of his time publishing under his real name, Charles Lutwidge Dodgson. Obviously, all these articles have both philosophical and historical significance. In the current issue, the readers can also find an article by Ülle Pärl from the recent past and by Małgorzata Durbas from the more distant one. As the core of our editorial staff works at the School of Business and Governance of Tallinn University of Technology, it is quite important to cover interesting developments in teaching business, economics and management in Estonia. The paper by Dr. Ülle Pärl fulfils this task.

Last but not least, we offer our readers a review of an interesting book about Lewis Carroll's paradox of inference by Jean Paul Van Bendegem. Editors of the reviewed book are Amirouche Moktefi and Francine F. Abeles. We plan to publish at least one book review in each forthcoming journal issue from now on.

Enjoy reading the first issue of the fifth volume of Acta Baltica Philosophiae et Historiae Scientiarum!

Peeter Mü̈̈rsepp

Editor-in-Chief 